\title{
A DINÂMICA DA URBANIZAÇÃO DESORDENADA NA FAVELA SURURU DE CAPOTE: SEGREGAÇÃO SOCIOESPACIAL E EXCLUSÃO SOCIAL
}

\author{
The dynamics of the the occupation in the Sururu Capote Fair: socioespatial segregation and social \\ exclusion
}

\author{
Andréa Geórgia Souza de Araújo * \\ Luciane Maranha de Oliveira Marisco **
}

\begin{abstract}
*Acadêmica do Programa de Pós-Graduação em Geografia da Universidade Federal de Alagoas - andreageorgia33@yahoo.com.br. ** Docente do Programa de Pós-Graduação da Universidade Federal de Alagoas - luciane.marisco@igdema.ufal.br.
\end{abstract}

Recebido em 07/05/2018. Aceito para publicação em 25/06/2018.

Versão online publicada em 10/08/2018 (http://seer.ufrgs.br/paraonde)

\begin{abstract}
Resumo: Este trabalho trata da investigação acerca da situação de exclusão (nas dimensões social, econômica, territorial e urbanística) e do processo de segregação socioespacial da população da Favela Sururu de Capote, localizada no bairro da Ponta Grossa em Maceió/AL. Essa população se encontra em um espaço suprimido, vivenciando um urbanismo de risco e uma situação econômica informal, sem o menor direito à cidade. Os objetivos dessa pesquisa são analisar e explicar os efeitos segregativos da população da Favela Sururu de Capote, excluída socialmente, em sua dimensão geográfica e territorial. 0 método utilizado é o materialismo histórico dialético. A pesquisa apontou até o momento um conjunto de indicadores negativos relacionados à infraestrutura e equipamentos coletivos.
\end{abstract}

Palavras-chave: urbanização; segregação socioespacial; exclusão.

\begin{abstract}
This research deals with the situation of extreme exclusion (in the social,economic, territorial and urban dimensions) and with the socio-spatial segregation process of the population of the Sururu de Capote slum, which is located in the district of Ponta Grossa in Maceió/AL. This population is in a restrained space, experiencing an urbanization of risk and an informal economic situation, without the minimum right to the city. The study analyzes and explains the segregating effects on the population of the socially excluded Sururu de Capote Slum in its geographic and territorial dimensions. The method used is the dialectical historical materialism. The research has so far identified a set of negative indicators related to infrastructure and collective equipment.
\end{abstract}

Key-words: urbanization; socio-spatial segregation; exclusion.

\section{Introdução}

O presente trabalho visa a investigação do processo de urbanização desigual na cidade de Maceió, mal planejada e vinculada apenas aos interesses políticos e à especulação imobiliária, dificultando acesso a moradia digna de uma grande parte da população da cidade, condicionando grupos à exclusão social, territorial e urbanística e, ao processo de segregação socioespacial.

As temáticas da segregação e exclusão, apesar de não serem novidades, estão muito distantes de se esgotarem, não apenas pela relação entre espaço e sociedade sempre dinâmica, mas porque sempre haverá novos estudos, reflexões e dúvidas. Nossa pesquisa se coloca diante da realidade do mundo contemporâneo, sendo referente a dissertação de mestrado que tem por objetivo propor uma abordagem específica acerca da situação de extrema exclusão e segregação espacial em suas diversas dimensões, tendo como foco de estudo a população da Favela Sururu de Capote, localizada às margens da Laguna Mundaú, no bairro da Ponta Grossa, na cidade de Maceió/AL há quase 40 anos.

0 trabalho justifica-se pela necessidade de repensar e investigar numa perspectiva geográfica, a 
crescente exclusão e o desarranjo espacial num processo de segregação e urbanização ilegal. Até o momento obtivemos resultados negativos através das entrevistas aos moradores sobre o acesso aos serviços públicos essenciais e recursos da cidade.

\section{Fundamentação teórica}

O tema ora estudado parte do pressuposto de que há a necessidade de reunir informações sobre o processo de exclusão social, exclusão territorial e exclusão urbanística, e sobre o processo de segregação socioespacial, a origem do processo de ocupação ilegal na região da Favela Sururu de Capote e da ilegalidade urbana na área investigada, para entendermos como os problemas se configuram nesse espaço. De origem francesa, exclusão social, segundo Costa (2001, p.19) "consiste numa situação dinâmica de privação, por falta de recursos". A exclusão envolve perdas sociais, econômicas, culturais, políticas e territoriais. Ainda de acordo com Costa (2001) a exclusão social está relacionada a noções de cidadania, de direitos humanos e democracia, traduzidas pelo acesso a um conjunto de sistemas sociais básicos do mundo do trabalho e da vida social mais ampla. A exclusão está relacionada a necessidades fundamentais ao homem como a saúde, educação, habitação, alimentação e infraestrutura na cidade onde habita.

Sobre o processo de segregação espacial podemos entender a separação da população no espaço geográfico, configurando espaços homogêneos. Essa separação pode se dar em função de diversos fatores tais como renda, cultura, gênero, raça, etnia, religião, categorias sócio-profissionais, etc. A esse respeito afirma Sposito (1996):

A segregação, a partir desse enfoque, pode, então, ser compreendida com o resultado de um processo de diferenciação que se desenvolve ao extremo e que leva, na cidade, ao rompimento da comunicação entre as pessoas, da circulação entre os sub-espaços, do diálogo entre as diferenças, enfim conduz à fragmentação do espaço urbano (SPOSITO, 1996, p.74).

O crescimento da Favela Sururu de Capote acontece à medida que aumenta a necessidade de habitação desses indivíduos e a busca pela sobrevivência na cidade fragmentada. A busca por um território onde construam uma identidade, o sentimento de pertencimento ao lugar ocupado, as relações afetivas e de poder num espaço delimitado pelos moradores, diante de um contexto histórico (social, econômico e político), que contribui para a expansão de uma cidade segregada, com grupos diferenciados principalmente pelo fator econômico, obrigados a modelar um espaço autoconstruído como as favelas.

Para Corrêa (2005), conforme referencia, também se faz necessário perceber que os grupos sociais excluídos, ao produzirem favelas, ocupando terrenos públicos ou privados, tornam-se, efetivamente, agentes modeladores, produzindo seu próprio espaço. 0 crescimento desordenado e não planejado da população da favela traz consequências impactantes na dinâmica da geografia espacial; estimulando o aumento da exclusão social, urbanística e territorial que se evidenciam cada vez mais na cidade, embora a sociedade hoje disponha de inúmeros recursos que possam auxiliar na inclusão da população excluída.

\section{Conforme indaga Schwartzman:}

Por que, com a abundância de recursos trazida pelas novas tecnologias de produção de massa, tantos permanecem excluídos, incapazes de ganhar a vida e participar plenamente de suas sociedades? Eles são pobres porque são vítimas do desenvolvimento capitalista ou de alguma espécie de discriminação social associada a eles? Ou há algo em suas mentes, e sua cultura e seu ambiente que os impeça de se integrar de forma adequada às classes, médias e assalariadas? (SCHWARTZMAN, 2004, p.74).

Ao tratar da exclusão em suas diversas dimensões procuramos também ter um entendimento sobre desigualdades sociais como causa da discriminação que ocorre em sociedades capitalistas como a nossa. De acordo com ROSSINI (2005), os possuidores de renda maior estão mais bem 
localizados em relação à infraestrutura urbana, pois possuem poder aquisitivo para adquirir a terra onde vivem, caracterizando o tratamento do espaço urbano como mercadoria, cujo preço é definido por certos atributos de mercado.

A Favela Sururu de Capote se constitui de grupos que vieram para a cidade de Maceió em busca de melhorias de vida na década de 1980 , porém, pela dificuldade encontrada no mercado de trabalho acabaram ocupando a região da Laguna Mundaú, surgindo assim a favela, que encontra na pesca do sururu$^{1}$ sua sobrevivência, iniciando uma nova organização do espaço urbano em consequência do processo de segregação socioespacial.

Na cidade de Maceió é possível verificar nitidamente o problema da distribuição socioespacial do acesso à moradia. Com a indústria começando a substituir as atividades de produção nas cidades, poucos imigrantes do interior conseguiram uma oportunidade de trabalho, dificultando a mínima condição de obter uma moradia regular com acesso digno à proteção, segurança e sobrevivência; ou seja, se tornaram parte dos agentes produtores do espaço como excluídos.

Na concepção de Santos:

A igualdade de direitos dos cidadãos requer condições semelhantes de acessibilidade aos bens e serviços públicos: (...) num território onde a localização dos serviços essenciais é deixada à mercê da lei do mercado, tudo colabora para que as desigualdades sociais aumentem (SANTOS, 2007, p.144).

O Estado tem a função de regulamentar o uso e ocupação do solo urbano e oferecer todos os serviços para a população, independente de sua condição econômica, porém, funciona de acordo com os interesses das classes dominantes, dos agentes produtores do espaço urbano apontados por CORRÊA (2005): os proprietários dos meios de produção, os proprietários fundiários, os promotores imobiliários e o Estado, e os agentes sociais excluídos, todos agindo de acordo com suas possibilidades e objetivos.

A princípio, o Estado tem que regular as relações políticas de classe, por ser um representante dos seus direitos políticos. Segundo Lojkine: 0 Estado é o "Agente principal da distribuição social espacial dos equipamentos urbanos para as diferentes classes e frações de classe" (1997, p.28). A ação do Estado determina a organização urbana a partir dos interesses de certos agentes, organizando e especializando a segregação das classes sociais sobre o território, acentuando o processo de exclusão social.

A ação do Estado é de fundamental importância para o modo como a cidade se espacializa e, neste sentido, Santos (1996, p.111) ressalta que "o próprio poder público torna-se criador privilegiado da escassez. 0 poder público, entretanto, não age apenas de forma indireta. Atua de forma direta na geração de problemas urbanos, ainda que prometendo resolvê-los". Damiani (1999) reflete na mesma direção ao afirmar que: a atuação do Estado no contexto urbano não ocorre de forma neutra, pois detém o papel de provedor de condições que favoreçam mais ou menos modelos urbanos segregacionistas.

No momento não há interesse político, social e econômico voltado para a produção de moradias regulares na região ocupada pela Favela Sururu de Capote, acentuando a situação de segregação socioespacial, reforçando o aumento da exclusão social, territorial e urbanística daquela população.

\footnotetext{
${ }^{1}$ A pesca do Sururu é uma atividade artesanal realizada por pescadores que são moradores da Favela Sururu de Capote, na Laguna Mundaú do Estado de Alagoas, que se constitui na extração do marisco que tem seu habitat na laguna e que serve de alimento para muitos alagoanos que sobrevivem dessa atividade a qual possui 4 etapas: a pesca, a limpeza, a distribuição e venda desse marisco. 0 sururu é um dos pratos típicos mais conhecidos da culinária alagoana e é o principal meio de vida dos moradores da Favela Sururu de Capote, por isso o nome dado à favela.
} 


\section{Material e método}

\subsection{Caracterização geral da área de estudo}

A área de estudo deste trabalho é a Favela Sururu de Capote, localizada às margens da Laguna Mundaú (figura 2), no bairro da Ponta Grossa, próximo ao centro da cidade de Maceió/AL (figura 1), numa distância de apenas $3 \mathrm{~km}$, e apesar dos moradores não se localizarem na periferia da cidade, estão submetidos a uma situação de vida excludente há quase 40 anos, em total descaso, com grande número de indivíduos sobrevivendo em barracos improvisados que são construídos com madeira extraída de forma ilegal das áreas de mangues.

Cobertos com plásticos encontrados e lonas recobrindo-os, os barracos são dispostos de forma desordenada e os moradores enfrentam diariamente condições insalubres de sobrevivência, em meio a doenças infecto-contagiosas, riscos de desabamentos, principalmente em épocas de chuvas fortes e incêndios por conta das ligações elétricas clandestinas dentro dos barracos; sendo assim, estão expostos a riscos de vida constantemente.

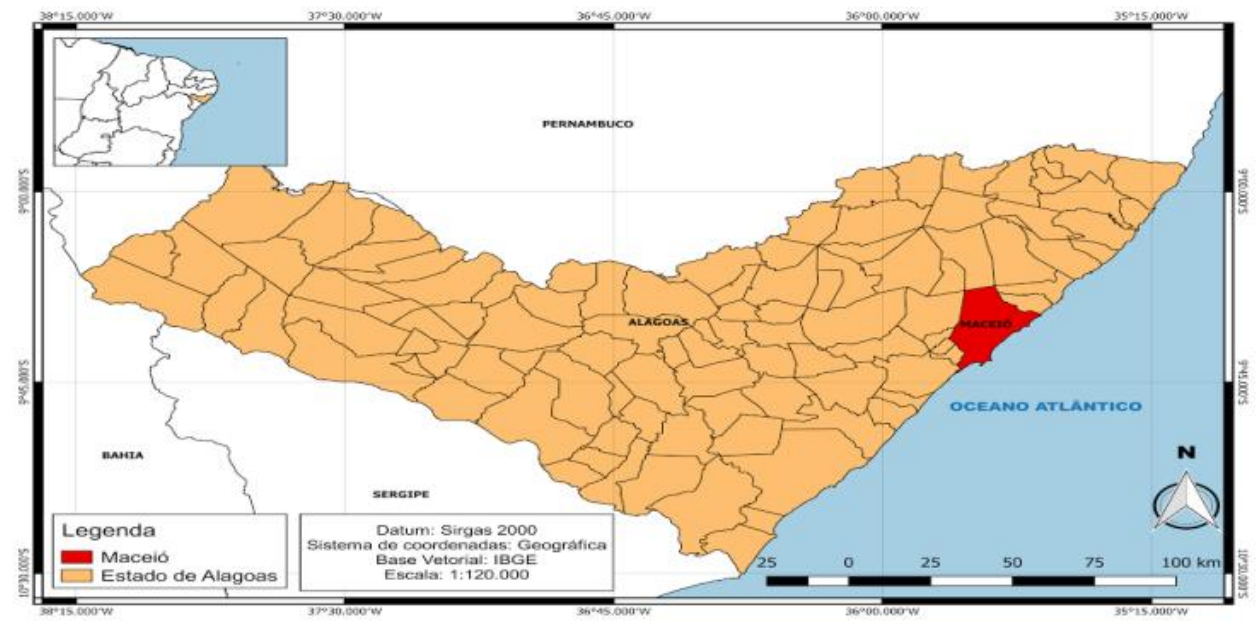

Figura 1: Mapa de localização da cidade de Maceió no estado de Alagoas Fonte: Base vetorial IBGE/Portal Alagoas em dados e informações. Georreferenciamento e elaboração cartográfica próprios.

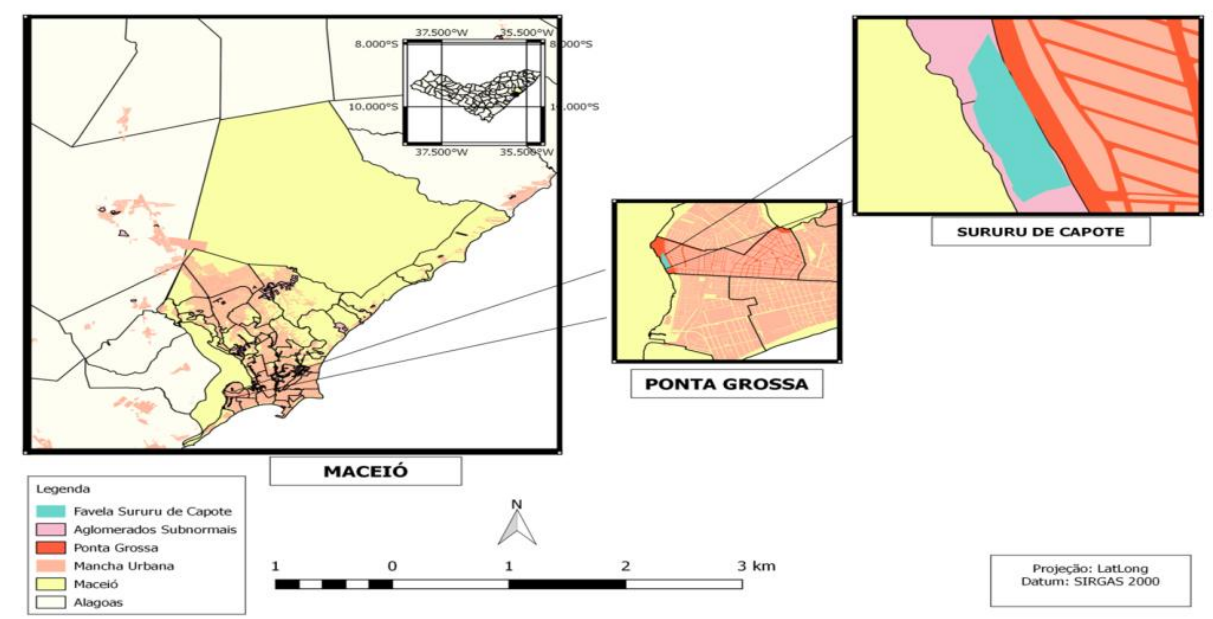

Figura 2: Mapa de localização da Favela Sururu de Capote em Maceió/Al Fonte: Base vetorial IBGE/Portal Alagoas em dados e informações. Georreferenciamento e elaboração cartográfica próprios. 


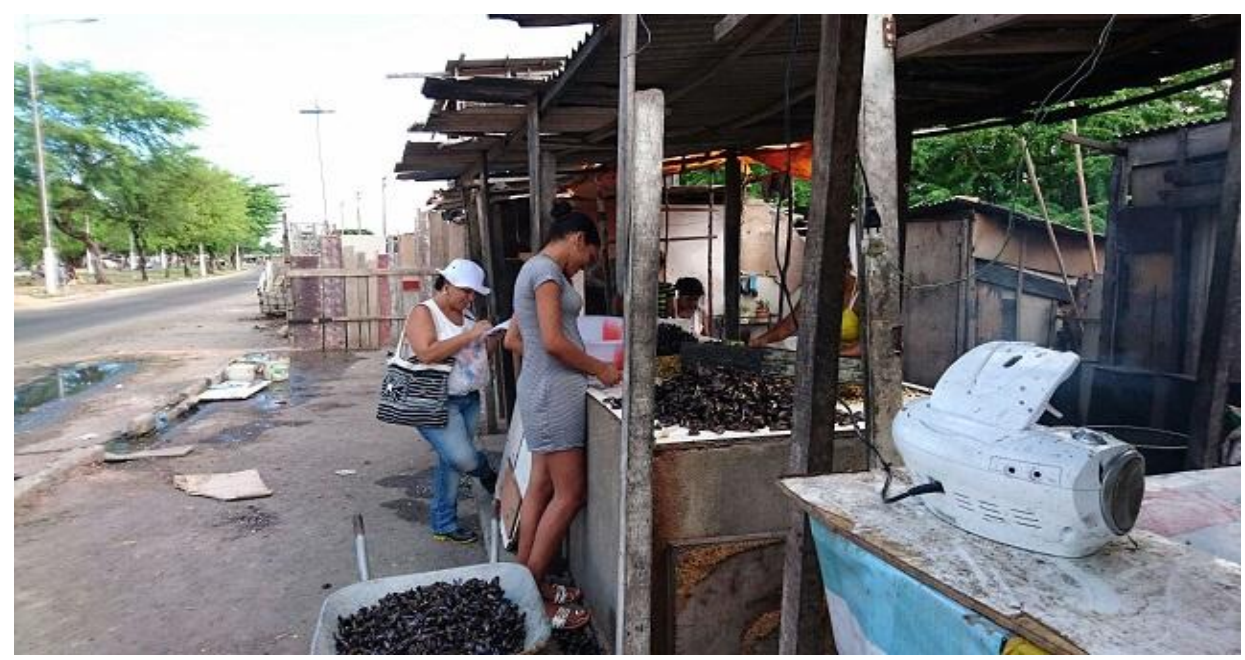

Figura 3: Moradores da Favela na venda do sururu da Laguna Mundaú, Maceió/Al

Fonte: Pesquisa de campo (Abril/2017).

\subsection{Descrição da pesquisa}

O método utilizado em nossa pesquisa é o materialismo histórico dialético, o qual se baseia na argumentação, discussão, confronto de ideias, entendendo a realidade de forma dinâmica e totalizante, onde os fatos sociais só podem ser entendidos considerando um conjunto de variáveis, e não de forma isolada; e a metodologia é composta por pesquisa bibliográfica, documental, coleta de informações pertinentes em órgãos públicos como: SLUM, SEINFRA, SMHPS, SMS, SEMAS e SEMED, além das visitas à Favela Sururu de Capote para observações diretas, registros de fotos, entrevistas e aplicação de questionários aos moradores*.

Fazendo uso estatístico para a coleta de dados da população investigada, foi feito o dimensionamento amostral de 153 questionários de acordo com o delineamento amostral do total populacional da favela em estudo (população total de 353 moradores), com posterior tabulação dos dados coletados e, construção de gráficos e tabelas.

Chegamos ao número da população total através da líder das marisqueiras, pois até o momento,

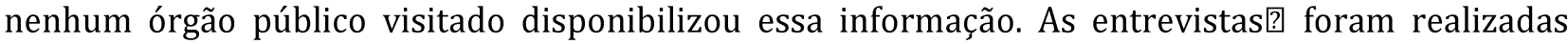
com os chefes de família, respondendo perguntas sobre o processo de ocupação e, perguntas de caráter socioestrutural e econômico.

\section{Resultado e discussão}

Os indicadores urbanísticos até o momento analisados confirmam o extremo grau de exclusão urbanística que essa população está submetida, e que nesses 40 anos tem reforçado ainda mais, devido a ausência de políticas públicas direcionadas a essa parcela da população. Apresentamos a seguir alguns dados que revelam a vulnerabilidade social e como o direito à cidade é negado em todas as suas dimensões. A pesquisa se encontra em andamento e, portanto as análises são parciais. 


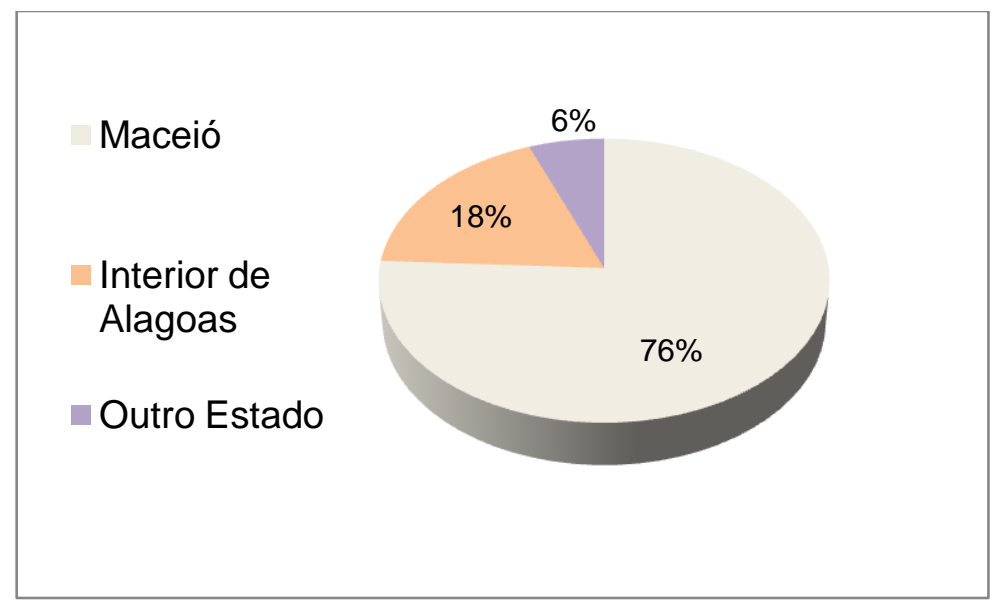

Gráfico 1- Cidade de origem/naturalidade

Fonte: Elaborados pela autora (2017).

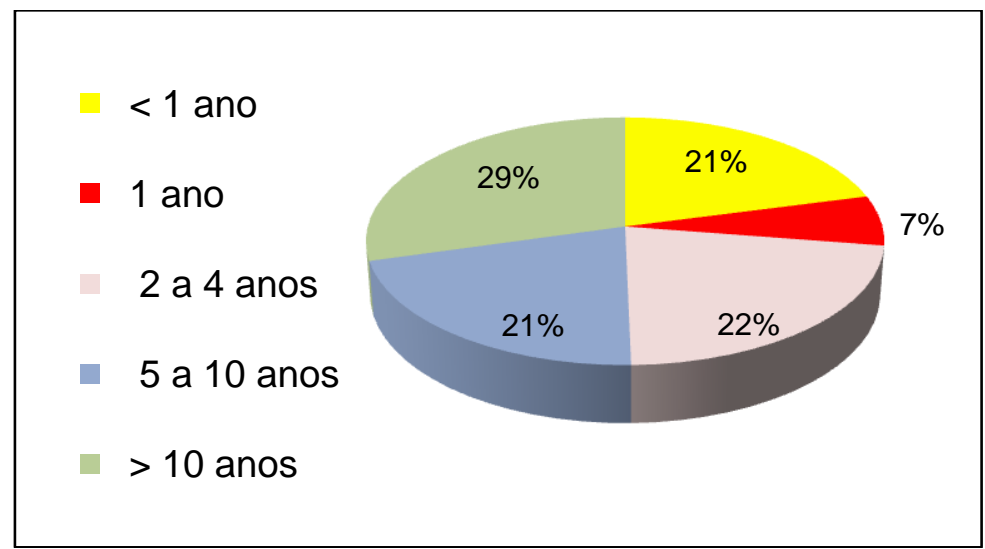

Gráfico 2- Tempo de residência na favela

Fonte: Elaborados pela autora (2017).

O gráfico 1 ratifica que a maior parte dos moradores da Favela Sururu de Capote são naturais da cidade de Maceió, correspondendo a $76 \%$ do total de entrevistados, incrementada por $18 \%$ de residentes oriundos do interior do estado de Alagoas, e mais 6\% provenientes de outros estados.

0 gráfico 2 mostra que a favela é composta principalmente por moradores com ocupação há mais de 10 anos, porém, traz um dado preocupante, já que $21 \%$ da sua população se fixou há menos de 1 ano, concluindo assim, que mesmo com toda falta de infraestrutura e das condições sub-humanas de sobrevivência, essa comunidade continua sendo uma alternativa para aqueles que não dispõem da mínima condição de habitabilidade.

Os moradores também responderam sobre a infraestrutura local, que diz respeito à destinação dos resíduos sólidos/lixo produzidos na comunidade local e o lançamento dos efluentes domésticos como observamos nas figuras 3 e 4 respectivamente. 


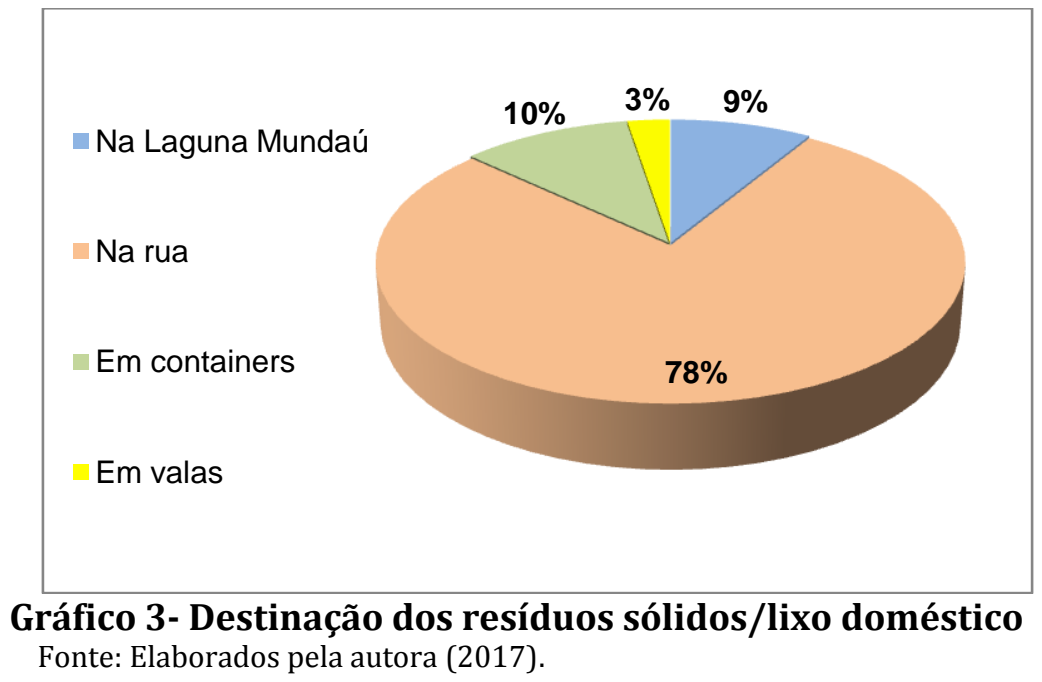

Fonte: Elaborados pela autora (2017).

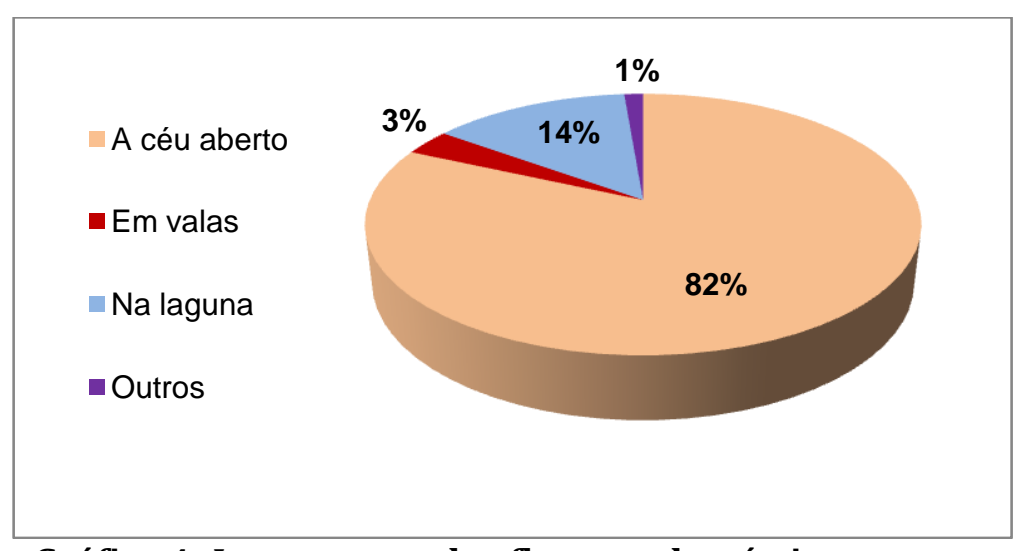

Gráfico 4- Lançamento de efluentes domésticos

Fonte: Elaborados pela autora (2017).

0 gráfico 3 indica que a maior parcela do lixo produzido é acumulado na rua pelos próprios moradores, esse procedimento é justificado pelo fato da Superintendência de Limpeza Urbana de Maceió (SLUM) não realizar a coleta de forma regular, além de disponibilizar poucos containers como podemos observar no gráfico que é apenas utilizado por $10 \%$ dos moradores.

Já o gráfico 4 indica que o lançamento de efluentes domésticos é feito em grande parte a céu aberto por não haver infraestrutura de saneamento básico, é destacado ainda, que $14 \%$ desses efluentes são lançados diretamente na laguna.

Por fim, o destaque para as principais fontes de renda, o nível de escolaridade e acesso à saúde pública. Os dados foram mencionados de forma subseqüente nos gráficos 5, 6 e 7 . 


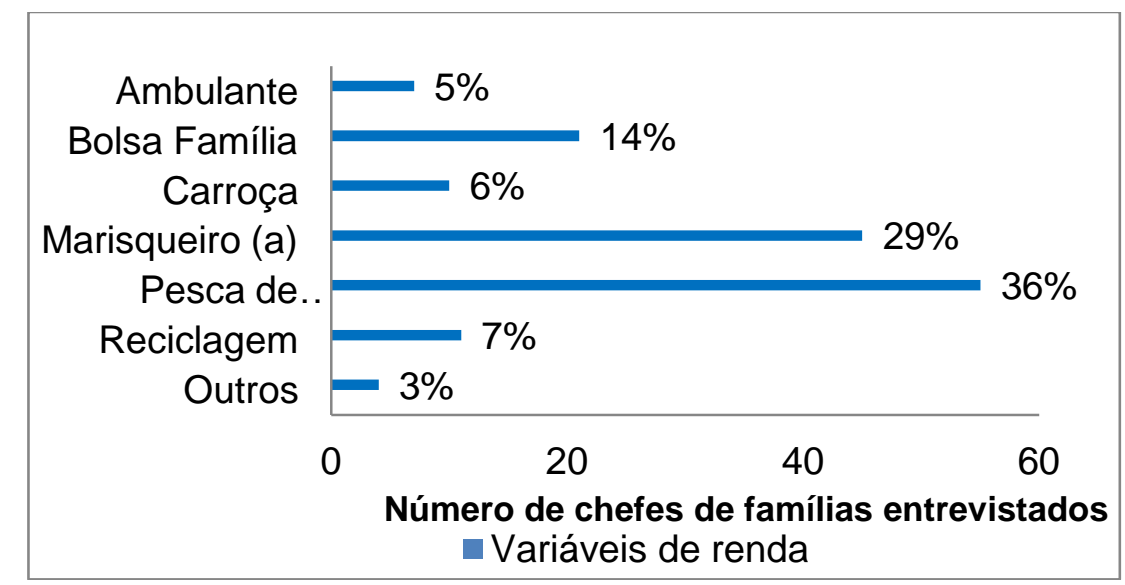

Gráfico 5 -Principais fontes de renda

Fonte: Elaborados pela autora (2017).

De acordo com o gráfico 5, fica evidente que praticamente toda economia dos moradores da favela Sururu de Capote está vinculada às atividades informais, sendo $65 \%$ desta economia movimentada pela pesca do sururu e a atividade de marisqueiro (a). Há um número significativo de famílias, com um percentual de $14 \%$ de moradores que sobrevivem apenas através do programa social do governo federal, 0 Bolsa-Família. 0 gráfico 6 aponta o grau de escolaridade dos moradores da favela, indicando que $73 \%$ dos moradores entrevistados possuem o nível fundamental incompleto e um percentual significativo de $13 \%$ são analfabetos.

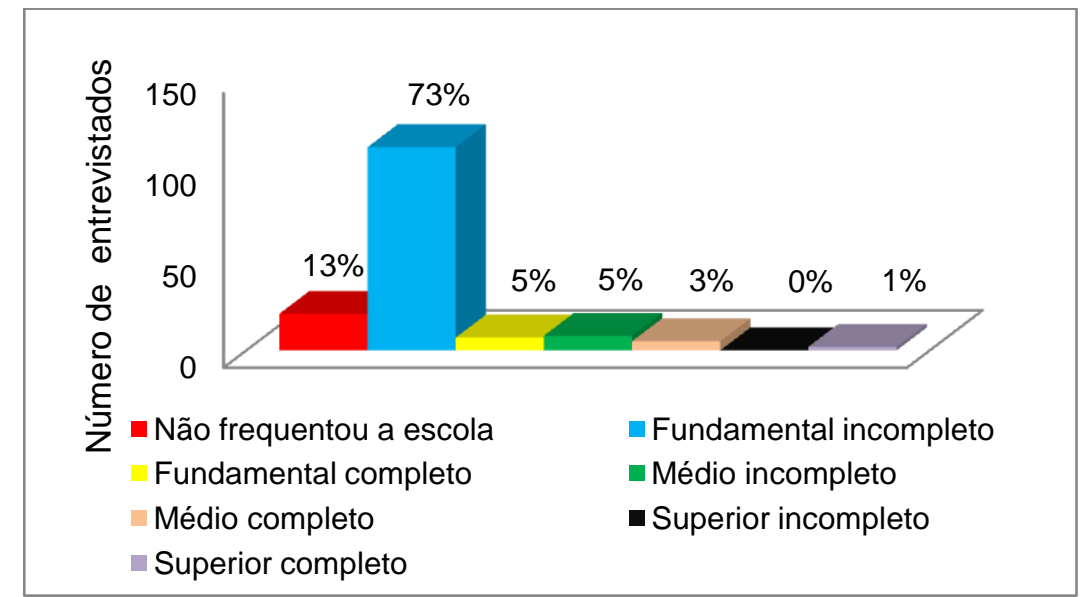

\section{Gráfico 6- Nível de escolaridade}

Fonte: Elaborados pela autora (2017). 


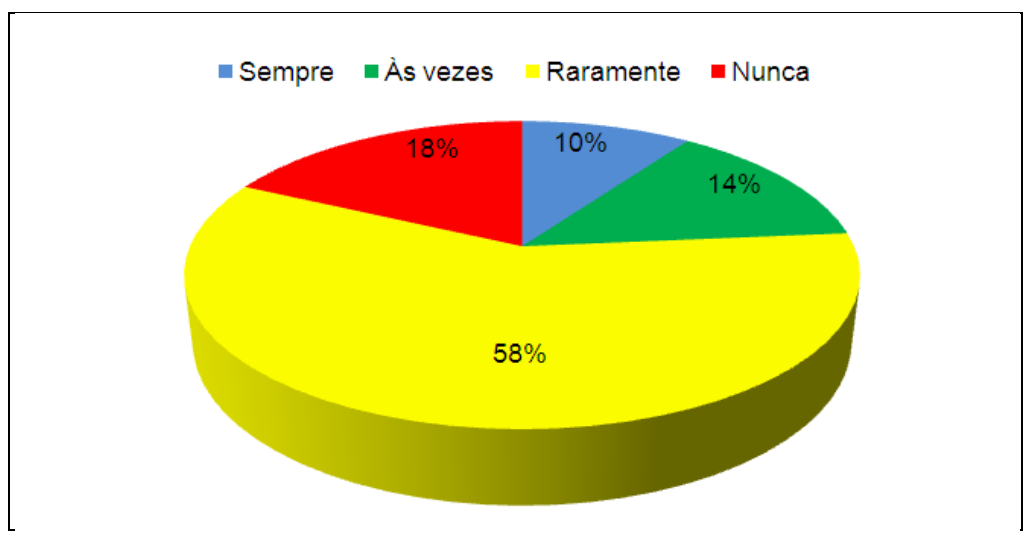

Gráfico 7- Acesso à unidade de saúde mais próxima no bairro da favela

Fonte: Elaborados pela autora (2017).

No gráfico 7, os indicadores apontam que 58\% dos moradores raramente consegue atendimento médico nas unidade de saúde pública do bairro, seguido por $18 \%$ dos que nunca tiveram atendimento médico e apenas $10 \%$ dos entrevistados tem acesso aos atendimentos médicos pelo SUS-Sistema Único de Saúde.

\section{Considerações Finais}

Essa pesquisa está em fase de desenvolvimento, entretanto, os dados preliminares nos permitem afirmar como a ausência do Estado para tratar a situação da população que reside na Favela Sururu de Capote, e que se perpetua há pelo menos 40 anos no local, tem reforçado o processo de segregação e exclusão da mesma, como um sistema que se retroalimenta, ou, seja, a segregação socioespacial reforça os processos de exclusão social, territorial, urbanística e vice-versa.

Na tentativa de inclusão e interação com a sociedade constroem seu próprio território, criando a sua própria "territorialidade", com o que esse lugar significa ou representa para esses indivíduos que são vítimas de uma sociedade opressora e desigual, pois é dever do Estado suprir essa parcela da cidade e sua população das condições mínimas de habitabilidade, e acima de tudo do direito a cidade preconizado por LEFEBVRE (2001) em sua obra 0 direito à cidade, fundamental para que possam viver com dignidade.

\section{Referências}

Alagoas em dados e informações - Malha digital bairros de Maceió. Disponível em http://dados.al.gov.br/. Acesso em 25 de maio de 2017.

COSTA, A. Exclusões sociais. Cadernos democráticos, 2.Edição Gradiva Publicações, 2001.

CORREA, R. L. O Espaço Urbano. São Paulo: Ática, 2005.

DAMIANI, A. L. As contradições do espaço: da lógica (formal) à (lógica) dialética, a propósito do espaço. In: DAMIANI, A. L.; CARLOS, A. F. A.; SEABRA, O. C. de L. O espaço no fim de século: a nova raridade. São Paulo: Contexto, 1999.

LOJKINE, J. O estado capitalista e a questão urbana. 2ª ed. São Paulo: Martins Fontes, 1997. 
LEFEBRVE, H. O direito à cidade. São Paulo: Editora Moraes, 2001.

INSTITUTO BRASILEIRO DE GEOGRAFIA E ESTATÍSTICA-IBGE. Malha digital municipal. Disponível em: http://www.ibge.gov.br. Acesso em 25 de maio de 2017.

ROSSINI, C. C. A Segregação na Distribuição dos Equipamentos de Infra-Estrutura Urbana na Cidade de Santa Maria/RS.2005. 135 f. Dissertação (Mestrado em Geografia)- Universidade Federal de Santa Catarina. Centro de Filosofia e Ciências Humanas, Florianópolis, SC, 2005.

SANTOS, M. A Natureza do Espaço: Técnica e tempo, razão e emoção. São Paulo: Editora Hucitec, 1996.

SANTOS, M. O Espaço do Cidadão. 7a ed. São Paulo: Edusp, 2007.

SCHWARTZMAN, S. Pobreza, exclusão social e modernidade: uma introdução ao mundo contemporâneo. São Paulo: Augurium, 2004.

SPOSITO, M. E. B. Reflexões sobre a natureza da segregação espacial nas cidades contemporâneas. Revista de Geografia AGB, Dourados, v.4. n.1, p.71-85, set./dez. 1996. 